\title{
Comparison of Repair Costs for Small and Mid-Sizes Farm Machinery in Malaysian Oil Palm Plantation
}

\author{
Siti Nabilah Samsudin", Darius El Pebrian ${ }^{\# 1}$, Ajeng Jok Wan* \\ \# Faculty of Plantation and Agrotechnology, Universiti Teknologi MARA Melaka, Kampus Jasin, \\ 77300 Merlimau, Melaka, Malaysia. \\ * Faculty of Plantation and Agrotechnology, Universiti Teknologi MARA, \\ 40450 Shah Alam, Selangor Darul Ehsan, Malaysia. \\ ${ }^{1}$ Corresponding authore-mail:darius@melaka.uitm.edu.my
}

\begin{abstract}
Farm machinery has been tremendously used to perform laborious tasks and speed-up the in-field operations in Malaysian oil palm plantation. In line with the significant increase in farm machinery usage in Malaysian oil palm plantation, hence, repair costs of farm machinery should be well-managed. Failure to do so may result in the plantations profits will be affected. This study aims to analyze and compare the current data of repair costs for small and mid-sizes farm machinery that are commonly used in Malaysian oil palm plantation. Besides, this study also aims to update and adapt the values of repair factors for cumulative repair and maintenance $(\mathrm{Crm})$ costs model of farm machinery in Malaysian oil palm plantation. The relevant data were collected through a survey that was carried out at several oil palm plantations in Melaka and Negeri Sembilan states of Malaysia. The findings indicated the common sizes of farm machinery used Malaysian oil palm plantation were in the range of small-size (28HP) to mid-size (75HP). It was found that annual average repair costs of mid-size farm machinery were $60.08 \%$ higher than the small-size one.

Meanwhile, mean ages of mid-size farm machinery were also $80.7 \%$ longer than the small-size one. The values of repairs factors 1 $(R F 1)$ and repairs factor $2(R F 2)$ for cumulative repair and maintenance costs model $(\mathrm{Crm})$ of farm machinery in Malaysian oil palm plantation were 1.4061 and $\mathbf{1 . 6 5 8 8}$, respectively. Conclusively, the findings of the study can give a valuable contribution to the oil palm plantations management in developing their strategic planning concerning the allocation of overall costs of farm machinery.
\end{abstract}

Keywords - repair costs; mechanization; oil palm plantation; farm machinery; Malaysia.

\section{INTRODUCTION}

Malaysia is currently one of the largest world's exporters of palm oil. As reported by MPOB [1], this country produces almost $11 \%$ and $27 \%$ of the world's oils and fat, respectively. In particular, Malaysia supplies about $47 \%$ of the world's stock of palm oil. Nowadays, being a major crop, the oil palms are planted on 4.49 million hectares of land in Malaysia. Efforts must do continue to increase oil palm productivity through the introduction of new technologies and diversify various methods in the oil palm plantations. Among the achievements gained from the introduction of new technologies is the implementation of mechanization that has been proven to be capable of contributing and improving workers' productivity in oil palm plantation.

As a central pillar in implementing farm mechanization, farm machinery has become significant input in accelerating crop production systems in Malaysia. One of the indicators for the matter is the statistical data compiled by the
FAOSTAT [2], which shows the Malaysian import value of agricultural tractors are tremendously increasing from about 31 million USD in 2004 to 90 million USD in 2008. The import value of agricultural tractors for the country in 2008 was also recorded as the second highest after 278.175 million USD for fertilizers manufactured. However, the import value of tractors is higher than other inputs such as pesticides (54.33 million USD), insecticides (22.729 million USD), fungicides (11.652 million USD) and herbicides (10.957 million USD).

The use of farm machinery have also given significant impact to the oil palm plantation industry through increasing productivity and reducing costs. The machinery has successfully reduced the time for plowing, harvesting and evacuating oil palm fresh fruit bunch (FFB), collecting free fruits, fertilizer application and pest and disease control at the field. Specifically in harvesting operation, for example, the labor requirements reduced by $50 \%$ with an additional 
saving approximately $30 \%$ in cost. Oil palm harvesting requires labor approximately at $87 \%$ [1].

Repair and maintenance costs are one of the critical farm cost components that need special attention to the massive use of farm machinery in oil palm plantations. Siemens et al. [3] stated repair costs consist of all expenditure for parts and labor for repairs made in a shop or on the farm. The repair costs for a specific machine is difficult to predict, and it will vary based on the geographical section because of the difference in soil, crops, climate, and operators. Hunt and Wilson [4] added repairs costs are also influenced by the degree of machine maintenance, adjustments, load factors, design, and factory errors. According to [4], the anticipated annual cost of repair for any one machine is highly uncertain. Plowshares, cutter bars, for example, will wear with the use and will need periodic replacing at different intervals for different conditions. However, Siemens et al. [3] stated the repair and maintenance costs are about typically account for $10 \%$ to $15 \%$ of the total costs related to agricultural equipment and will increase with the age of equipment.

Repair costs of the tractor in developing countries were found about $8 \%$ of operation costs for diesel tractors as reported by Inns [5]. This data was estimated from the costs of $52 \%$ of tractors operation in the developing countries. He also said the operating costs were likely to be at least twice that in developed countries. The difference was due to the costs of repairs and poor service.

Several researchers have developed some model to estimate the repair and maintenance costs [6]-[13]. For example, Lips and Burose [13] applied a two-steps procedure. In the beginning step, annual repair and maintenance costs from a cross-sectional survey were used, which are thus not dependent on information concerning accumulated work units, which are particularly difficult to determine for non-motorized machines (e.g., accumulated hectares for a rotary harrow from purchase to date of survey). In the second step, repair and maintenance cost functions were estimated on an annual basis instead of for a single work unit. Thirdly, annual utilization was used as an explanatory variable, and following that additional machinespecific variable such as working width were utilized. Finally, in order to derive the repairs and maintenance factors (RMF), the annual costs are summarized over the length of service for all years, instead of integrating the cost function per work unit. For this, different operating version consisting of annual utilization and matched service lengths are assumed.

It is believed that the current findings were only more compatible and applicable with their respective countries of origin with their specific operating conditions and type of crops cultivation. Malaysian oil palm plantations have its specific conditions which are different with the countries stated in the studies due to differences in farm machinery operation, land topography, crop and weather conditions, repair policy and operator's skills. These factors have caused further investigation is needed to be carried out in order to suit the findings from the previous studies would be adaptable and applicable with oil palm plantation conditions. Furthermore, the repair costs and factors that cause variation among farm machinery repair costs have not recently been systematically studied in the oil palm plantation. In light of above problems, there is a need to record and analyze repair costs data of farm machinery in oil palm plantation, and the area in which the repair costs could be further reduced by improving the operation and innovating the farm machinery design. The cost record of farm machinery should be given considerable attention since it would provide the benefits such as deductible expenses for income tax purpose, cost of production data, and information on which to base equipment replacement decisions [4].

The objectives of this study are to analyze and compare the current data in repair costs of farm machinery in Malaysia oil palm plantations. Besides, the effect of farm machinery age, power, and annual hours of use on the repair costs was examined. This study also aims to update and adapt the repair factor $1(R F 1)$ and repair factor $2(R F 2)$ values of the established repair costs model by the ASABE [10], [14] in respect to specific farm machinery operations oil palm plantation.

\section{MATERIALS AND MethodS}

The present study compiled data on the repair cost of farm machinery from a survey carried out in three oil palm estates at Melaka and Negeri Sembilan states of Malaysia. The estate's topography ranges from flat to undulating areas.

The data of repair cost were collected from information provided by the estate's management from December 2014 to February 2015. The data includes the initial purchase price of farm machinery, age, hours of annual use, farm machinery power size, and annual repair costs. The selected estates utilize fully mechanized system in performing their daily operations.

Total amounts of 15 farm machinery, which represent about $90 \%$ of total farm machinery of the estate, were taken for samples. The sampled farm machinery consists of tractors as a universal prime mover, and also its attachments for main in-field operations in oil palm plantation such as nursery, crop planting, crops upkeep, and infield oil palm fresh bunch evacuation operations. Note, $47 \%$ of the total farm machinery ages from 0-10 years. These ages are considered as typical and save ownership period.

Meanwhile, $53 \%$ of the total farm machinery in this study is more than 11 years old and considered as risky machine life due to the danger of obsolescence [3]. The distribution of farm machinery ages are summarized in table 1 .

Descriptive statistic technique assisted by spreadsheet software was used to summarize the collected data. The management level of farm machinery repair costs in oil palm plantations was also analyzed. Three parameters including mean initial list price of farm machinery, the assumption of normal total usage of 5000 working hours, and the total repair costs during that period were considered in calculating the level of farm machinery repair management in oil palm plantations.

TABLE I

DiSTRIBUTION OF FARM MACHINERY AGE

\begin{tabular}{|c|c|}
\hline $\begin{array}{l}\text { Farm machinery age } \\
\text { (years) }\end{array}$ & $\begin{array}{l}\text { Percentage from total } \\
\text { sample (\%) }\end{array}$ \\
\hline $0-10$ & 47 \\
\hline 11 and above & 53 \\
\hline
\end{tabular}


Records of repair costs compiled by the Agricultural Engineering Department, University of Illinois, the USA concerning the management levels was used in the evaluation of repair costs for farm machinery in oil palm plantation [3]. The management levels are classified into three levels, e.g. good, average and poor management and measured by the proportion of total repair cost to the initial price of a tractor which is adapted from Siemens et al. [3].

Based on the adaptation, if the calculated proportion of the total repair costs compared to the initial list price of the tractor ranged from $13 \%$ to $17 \%$, thus it is considered as good management level. An average management level is judged when the proportion is in between $18 \%$ to $21 \%$, while poor management is stated when the proportion of $22 \%$ and above.

Non-linear power function regressions were also utilized to determine the $R F 1$ and $R F 2$ values for cumulative repair and maintenance costs $(\mathrm{Crm})$ model (expressed as a percentage of the list price). To develop repair factors (RF1 and RF2) values of farm machinery in oil palm plantation, the $\mathrm{Crm}$ models suggested by previous studies $[6,10,12,14$, $15]$ as in equation (1) were referred.

$$
C R M=R F 1\left(\frac{h}{1000}\right)^{R F 2}
$$

Where, $\mathrm{Crm}$ is the total cumulative repair and maintenance costs (expressed as the percentage of the list price of a machine), \%. $\mathrm{P}$ is the machine list price in current dollars, $\$$. In times of rapid inflation, the original list price must be multiplied by $(1+l)^{\mathrm{n}}$ where $l$ is the average inflation rate, and $\mathrm{n}$ is the age of the machine, year. $\mathrm{H}$ is the working hours accumulated by each machine, hours per year. $R F 1$ is the amount of $\mathrm{R} \& \mathrm{M}$ costs. $R F 2$ is the distribution of $\mathrm{R} \&$ $M$ costs during the estimated life of a machine.

\section{RESULTS AND DISCUSSION}

The mean of farm machinery initial list price in oil palm plantation in the study area was 14916 USD, which ranges from a minimum of 9000 USD to a maximum of 24550 USD. The farm machine ages also varies from a minimum of 2 years and maximum of 35 years, with a mean of 17 years, The common farm machinery used in Malaysian oil palm plantations are diverse from small -size with minimum power of $28 \mathrm{HP}$ to the large-size with maximum power of $75 \mathrm{HP}$, with a mean power of $60 \mathrm{HP}$.

This power size is less than that of the tractor power used in Arab Saudi, which ranges from 70HP to 325HP [9], and $78 \mathrm{HP}$ to $265 \mathrm{HP}$ tractors used in Northern Italy [6]. The mean for hours of annual use was 609 hours (minimum of 298 hours and maximum of 921 hours). These values were also lower than that of 798 hours annual use in Northern Italy [6] and average 970 hours in the USA [16]. However, the hours of annual use of farm machinery in Malaysian oil palm plantations was slightly higher than that of the Italian with an average of fewer than 500 hours [16]. Amount of hours of annual use of farm machinery will affect the repair and maintenance costs. According to Lips [11], the degree of machine utilization exerts a huge influence on accumulated repairs and maintenance costs. Thus, the accumulated repair and maintenance costs can be minimized if high annual utilization coupled with a short service life is applied. Table 2 summarized general information related to repair costs data of farm machinery in the study area.

TABLE II

SUMMARY OF FARM MACHINERY REPAIR COSTS DATA

\begin{tabular}{|l|l|l|l|l|l|}
\hline $\begin{array}{l}\text { Para- } \\
\text { meter }\end{array}$ & $\begin{array}{l}\text { Initial } \\
\text { list price } \\
\text { (USD) }\end{array}$ & $\begin{array}{l}\text { Age } \\
\text { (Year) }\end{array}$ & $\begin{array}{l}\text { Farm } \\
\text { machinery } \\
\text { power size } \\
\text { (HP) }\end{array}$ & $\begin{array}{l}\text { Annual } \\
\text { use } \\
\text { (hours) }\end{array}$ & $\begin{array}{l}\text { Annual } \\
\text { repair cost } \\
\text { (USD/year) }\end{array}$ \\
\hline Mean & 12520 & 18 & 55 & 609 & 897 \\
\hline SD & 5052 & 12 & 24 & 196 & 944 \\
\hline Min & 9000 & 2 & 28 & 298 & 26 \\
\hline Max & 24550 & 35 & 75 & 921 & 3477 \\
\hline
\end{tabular}

In this study, we defined small-size farm machinery is farm machinery with power size of less than $30 \mathrm{HP}$. Midsize farm machinery refers to farm machinery with a range of power size of $30 \mathrm{HP}$ to $80 \mathrm{HP}$. Farm machinery with power size of more than $80 \mathrm{HP}$ is grouped into large-size. In oil Malaysian palm plantations, it was found that the power sizes of farm machinery are assorted from small-size (28HP) to mid-size (75HP). Hours of annual use of farm machinery in oil palm plantation are also varied from low-annual use (298 hours) to moderate-annual use (921 hours). Mid-size farm machinery has higher annual hours of use as compared to the small size one. As illustrated in Figure 1, farm machinery with power size of $75 \mathrm{HP}$ has average annual hours of use of 611 hours or $4.75 \%$ longer than that of 582 hours by the 28HP. This condition occurs because mid-size farm machinery is more frequently utilized in the field operations rather than that the small one. Normally, midsize farm machinery becomes a universal prime mover and serves mostly various infield operations in oil palm plantations, such as nursery operations (Figure 2), holing for replanting (Figure 3), and pest control (Figure 4). Other than that, mid-size farm machinery was also used for mainline transport of collected FFB from field to the mil, and worker's transport in the field. All these operations require special implements that attached on the farm machinery or tractors. Commonly, all these special implements need a larger size farm machinery to operate at an optimum level.

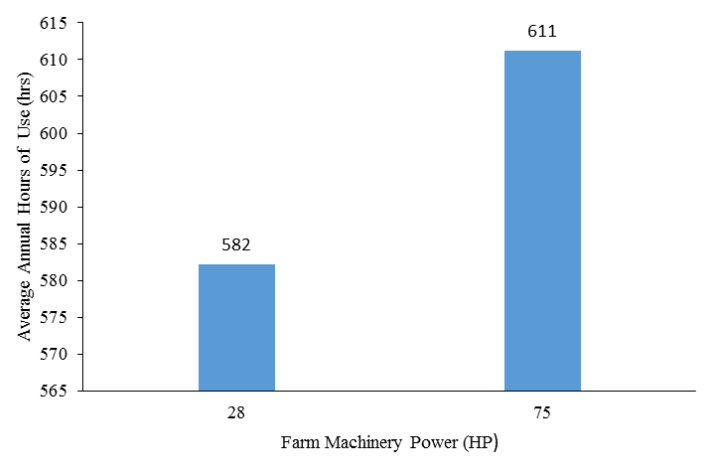

Fig. 1 Farm machinery power size against average annual hours of use. 


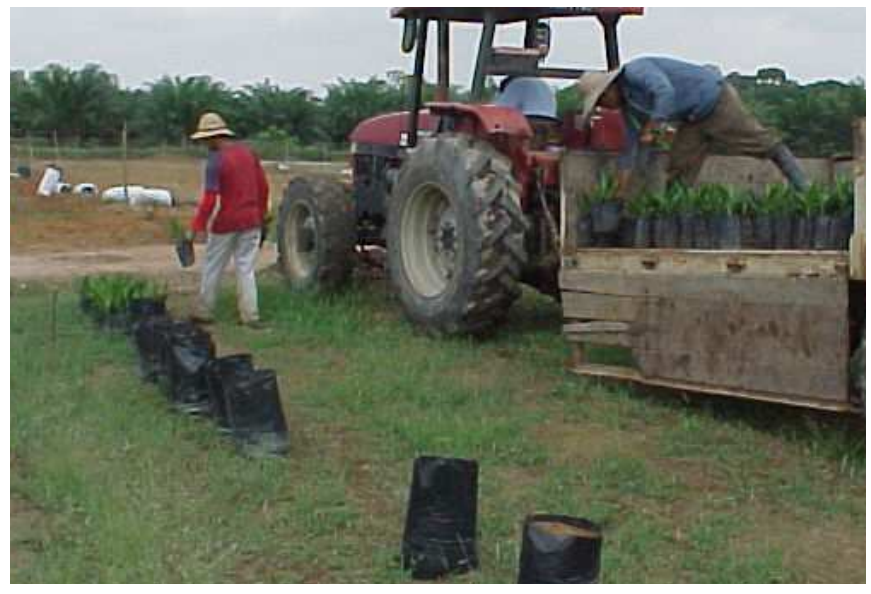

Fig. 2 Mid-size farm machine for nursery works.

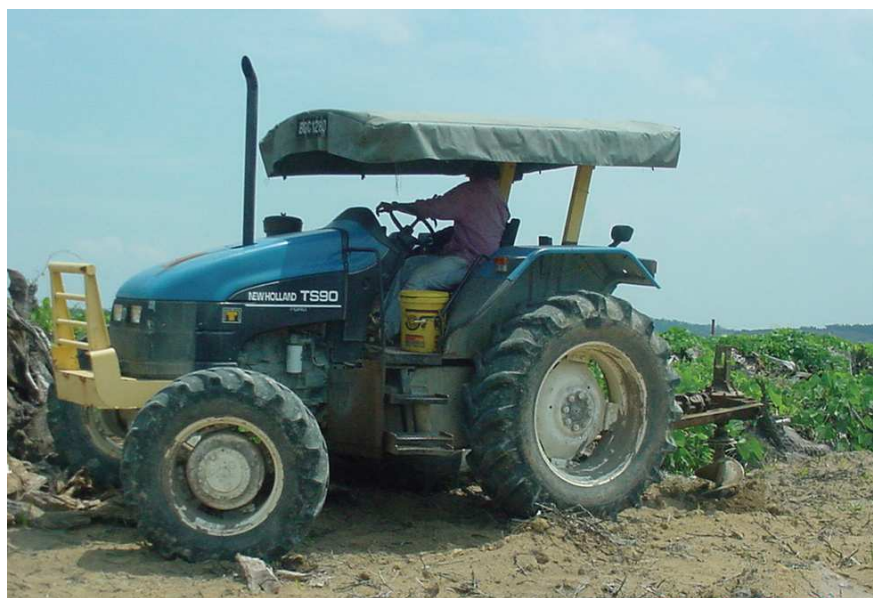

Fig. 3 Mid-size farm machinery for preparing planting hole [17].

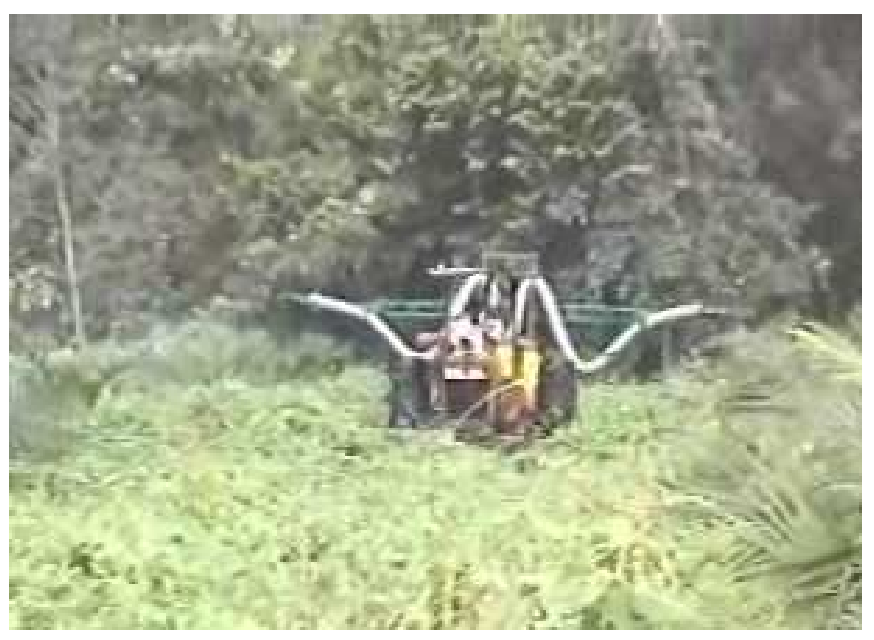

Fig. 4 Mid-size farm machinery for pest control [17].

Small-size farm machinery is generally being used for conducting a specialized operation such as oil palm fresh fruit bunches (FFB) evacuation and mature palm fertilizing operations (Figures 5 and 6). The usage frequency of midsize farm machinery for infield operations in oil palm plantation was 124 times in a year or $82 \%$ higher than that of 22 times a year of the small-size farm machinery [18]. As mentioned earlier, small -size farm machinery was preferred to be used by the plantation management for oil palm FFB evacuation operation because by having such size; it is easy for the machinery to traverse the harvesting path of oil palm plantation with high maneuverability. A mounted grabber with a trailer was usually attached to this farm machinery to carry out the oil palm FFB evacuation operation.

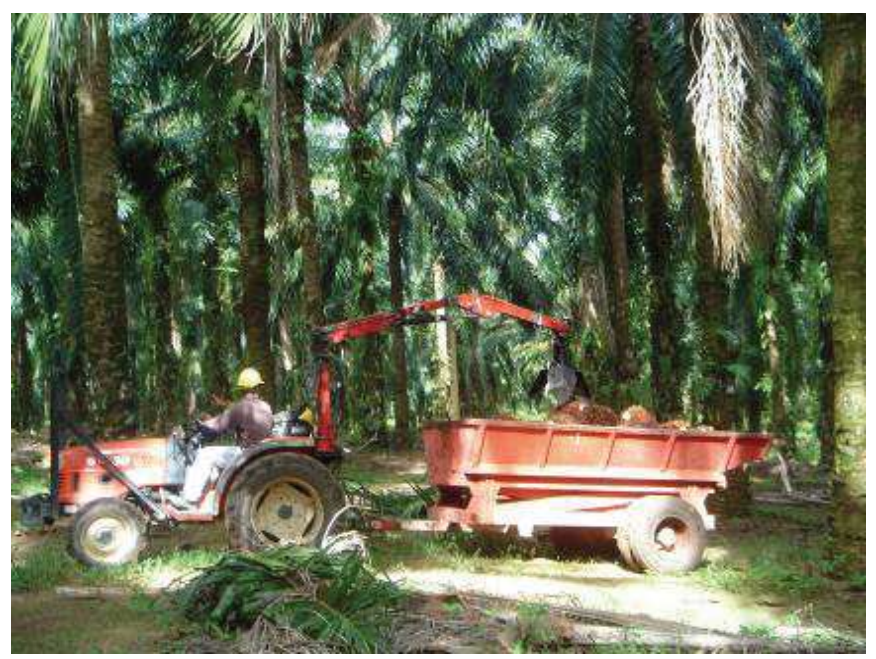

Fig. 5 Small-size farm machinery for oil palm FFB evacuation [17].

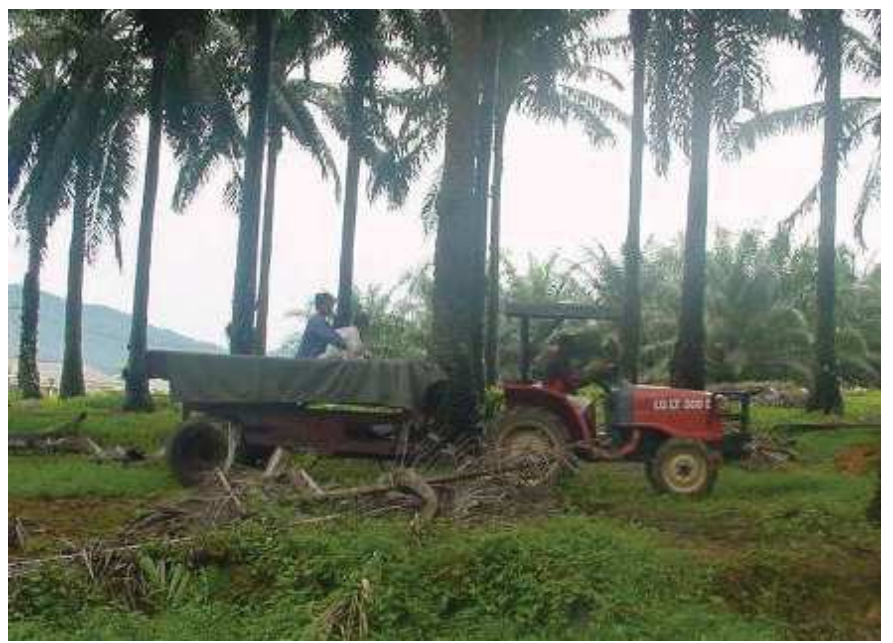

Fig. 6 Small-size farm machinery for fertilizing mature palm [17].

Generally, in the oil palm plantation, the mid-size farm machinery has longer machinery ownership as compared to small-size farm machinery. As presented in Figure 7, mean ages of mid-size farm machinery was 26 years or $80.7 \%$ longer than that of 5 years of small-size farm machinery. Trading or replacing farm machinery is one of the important strategies that should be implemented in machinery management. This is because farm machinery consumed a large portion of investments in the farm business. An example, from a study in Kansas farms, USA, by Langemeier and Taylor [19] and they found that machinery costs (including gas, oil, repair, depreciation, interest on investment, and insurance) account for $35.5 \%$ to $46.6 \%$ of crop production costs. Thus, to apply the management strategy in regards to this matter, the machinery should be regularly maintained, monitored, and traded or replaced. 
This is agreeing with Siemens et al. [3], who said that owning farm machinery for too long is not a reasonable manner for obtaining the best profit because it will increase repair and maintenance costs and the machinery would be easy to break down when needed most. Usually, machinery above 10-year old requires extensive repairs and may no longer reliable except for the short periods of time. It could be very risky to own any machinery or tractor over ten years could be precarious. Machine and to some extent tractors can become obsolete before they are worn out completely.

In the case of oil plantations, commonly, the oil palm plantations management were reluctant to trade or replace mid-size farm machinery because of the necessity of large investment in purchasing the new ones.

The management prefers to keep the mid-size farm machinery longer than the small-size ones in order to reduce the machinery costs. Although these mid-size farm machineries were more frequently used than the small-size farm machinery, however, as long as the machinery can perform the job properly, the management of the plantation considers the machinery is still feasible and reliable to be used.

On the contrary, small-size farm machinery as mentioned earlier was used for oil palm FFB evacuation. This operation was considered as the most critical operation in the oil palm plantation as it was related to the yields and palm oil quality from the oil palm FFB.

Using low reliability or worn-out farm machinery, of course, it will delay the oil palm FFB evacuation from the field to the mill for palm oil processing. This situation will increase the free fatty acids (FFA) content, which later it can lead reduction of quality of the palm oil.

This becomes a serious matter in the oil palm plantations and should be given considerable attention from the managers. The estate management has to avoid or minimize these situations, or else the palm oil mill management would penalize them. Finally, it will affect the company's overall profits. That is the reason why the machine for the oil palm FFB evacuation operation must have high reliability to complete the job on time.

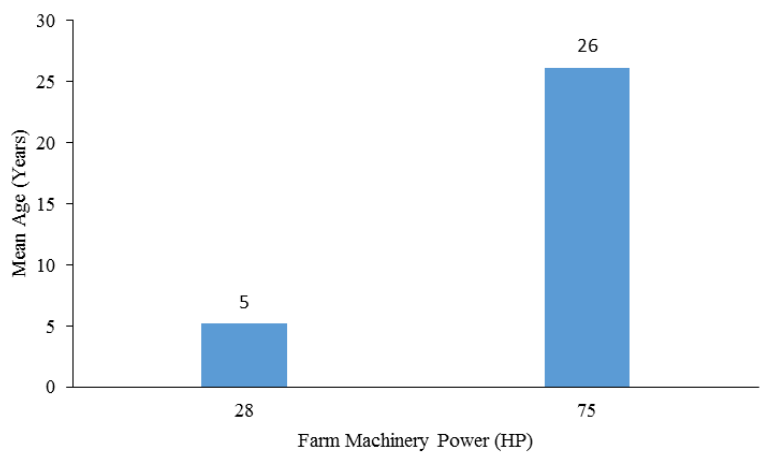

Fig. 7 Farm machinery power size against mean ages.

Figure 8 shows the annual average repair costs of midsize farm machinery (75HP) was 912 USD /year or $60.08 \%$ higher than that of 364 USD /year of the small-size ones (28HP). Heavy usage of the mid-size farm machinery in oil palm plantation operations has caused its annual average repair costs are higher than the small-size ones. This is consistent with Siemens et al. [3], who states that usually, repair costs are related to how much a machine is used. As mentioned earlier, mid-size farm machinery (tractor) is utilized as a multi-purpose prime mover. This machine assists the infield operations in oil palm plantations, such as nursery operations predominantly, holding soil for replanting, manuring, spraying, mainline transport, and worker's transport in the field.

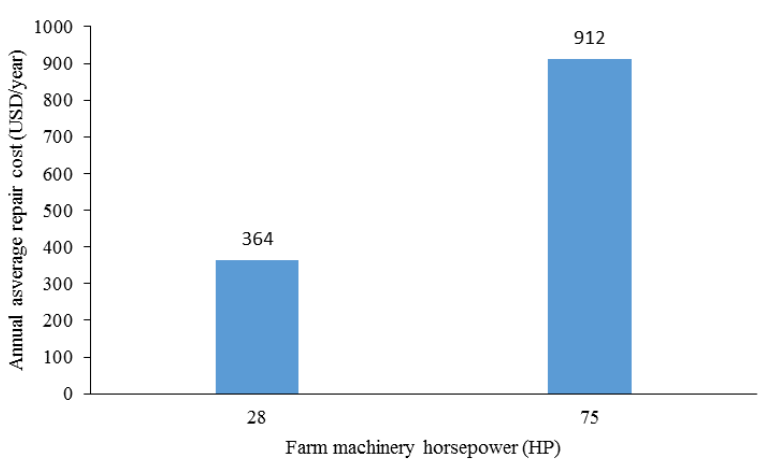

Fig. 8 Farm machinery power size against annual average repair cost.

A categorization of farm machinery management levels in oil palm plantation operations has been successfully developed in this study as indicated in Figure 9. The management levels are classified into three levels, e.g. good, average and poor management and measured by the proportion of total repair cost to the initial price of a tractor which is adapted from Siemens et al. [3].

Based the adaptation from [3], when the proportion of the total repair costs compared to the initial list price of the tractor ranging from $13 \%$ to $17 \%$ (maximum total repair costs at 1630 USD) is considered as good management level. An average management level is judged when the proportion is in between $18 \%$ to $21 \%$ (maximum total repair costs at 2174 USD), meanwhile poor management is stated when the proportion of $22 \%$ and above (repair costs starting from 2717 USD).

With mean initial list price of farm machinery at 12520 USD, mean annual use of 609 hours/year, and mean annual repairs costs of 897 USD /year (Table 1), thus, mean total repairs costs of farm machinery in oil palm plantation operation for 5000 hours was 7365 USD or $59 \%$ of initial list price of farm machinery. Such percentage falls into poor management level based on the adapted percentage category of management level as shown in Figure 9.

Higher percentage total repairs costs of farm machinery in oil palm plantation operations could be due to geographical sections. Veloo and Hitam [20] reported that land of oil palm plantations that suitable to be fully mechanized in Malaysia was only 194000 hectares. Veloo et al. [21] added, more than $50 \%$ of land areas in Peninsular Malaysia and Sabah are sloped, while more than $70 \%$ such as areas are located in Sabah.

Hence, operating farm machinery on challenging areas has affected their repair costs, especially costs for routine wear and routine overhauls to restore original performance of the farm machinery. This is agreeing with Siemens et al. [3], who mentions that geographical condition of a country can cause variation in farm machinery repair costs. Most 
geographical sections in oil palm plantation are undulating and slope areas.

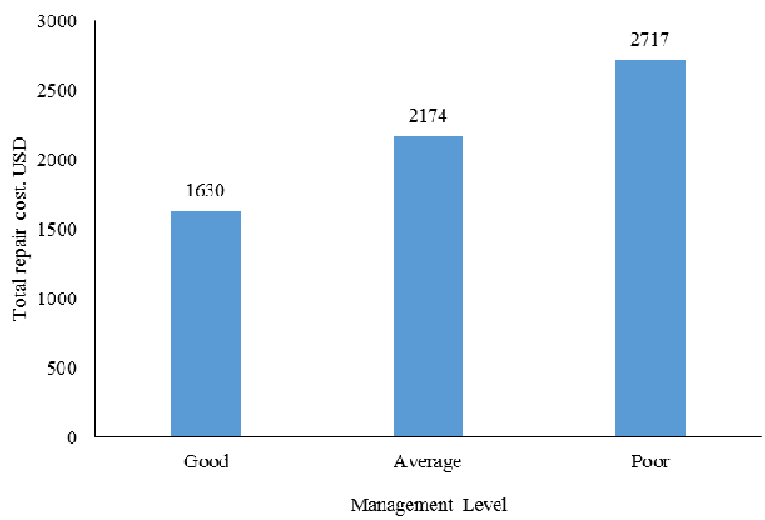

Fig. 9 Farm machinery management levels in oil palm plantation operations

The repair and maintenance cost for agricultural operations can be determined or defined by the repair and maintenance cost model $(\mathrm{Crm})$. For this study, it was shown that like most of the previously published studies, the power model presents the best cost prediction.

Thus, as shown in Figure 10, the trend of oil palm plantation $\mathrm{Crm}$ was similar to the trend of previously published studies [3, 10, and 14]. At 2000 hours utilization, the results showed that the oil palm plantation $\mathrm{Crm}$ was relatively 2.4 times higher than the $\mathrm{Crm}$ by ASABE [10], but it was over 2 times smaller than that the $\mathrm{Crm}$ reported by Khoub bakht et al. [15]. The developed non-linear relationship (Figure 10) between accumulated working hours and accumulated repair cost has successfully found out the values repairs factor $1(\mathrm{RF} 1)$ and repairs factor 2 (RF2) for $\mathrm{Crm}$ model for farm machinery in oil palm plantation were 1.4061 and 1.6588, respectively. Thus, the developed Crm model for farm machinery in oil palm plantation would be:

$$
C R M=R F 1\left(\frac{h}{1000}\right)^{R F 2}
$$

Meanwhile, it was relatively almost the same as Calcante et al. [6]. At 12000 hours, the Crm for oil palm plantation was relatively doubled when compared to the ASABE [10], [2] and Calcante et al. [6]. However, it was still lower than the $\mathrm{Crm}$ by Khoub bakht et al. [15]. The differences between the present study and the ASABE [10] were caused mainly by the operations characteristics of the oil palm plantation when compared to the operation characteristics of wheat cultivation in the USA.

In oil palm plantation, the farm machinery was utilized in different ways as compared to other cultivation. Farm machinery was mostly used to carry loads in-field. Farm machinery was rarely utilized to carry out the operations itself, unless the particular operation has been mechanized in oil palm plantation such as fully mechanized manuring and weeding, in which both operations will require special implement to be attached to the farm machinery.

In USA's wheat cultivation, various operations have been fully mechanized, simpler in operation, and the standards operating procedures have been established as well. Thus, repair and maintenance costs for USA's wheat cultivation operations were efficient compared to oil palm plantation operations. This situation was also true when compared to the Crm of Italian [6] and Iranian [15].

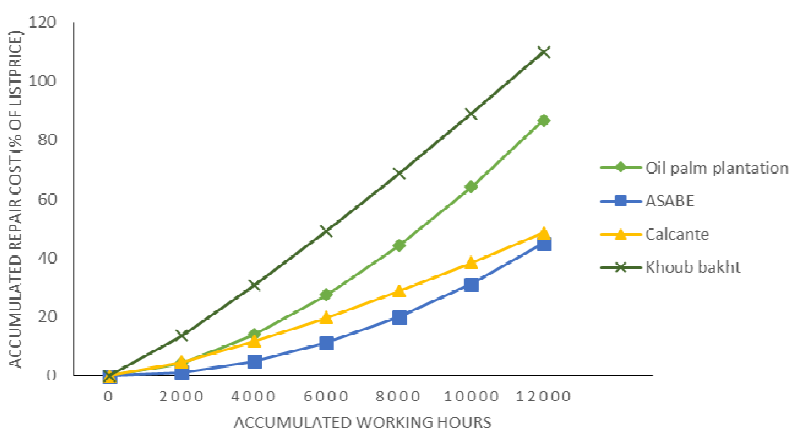

Fig. 10 Comparison between the Crm models developed by this study and previous published studies $[6,10,15]$.

\section{IV.CONCLUSION}

This study has successfully recorded, discussed and analyzed and compared repair costs of farm machinery in oil palm plantations in Malaysia. Relevant information on repairs costs such as machine age, power size, and annual hours of use was also examined.

In oil Malaysian palm plantations, farm machinery age ranges from 2 to 35 years old. The power size of farm machinery was assorted from small-size (28HP) to mid-size (75HP). Hours of annual use of farm machinery in oil palm plantation were also varied from low-annual use (298 hours) to moderate-annual use ( 921 hours).

The annual average repair costs of mid-size farm machinery (75HP) were found to be 912 USD /year or $60.08 \%$ higher than that of $364 \mathrm{USD} /$ year of the small-size ones (28HP). Based on the calculated total repair costs for 5000 hours of use, it can be stated that farm machinery management in oil palm plantation operations falls into poor management level.

At 2000 hours utilization, the cumulative repair and maintenance costs model $(\mathrm{Crm})$ for farm machinery in Malaysian oil palm plantations were also 2.4 times higher than the ASABE standards, but lower than the Crm of Iranian farm machinery and relative almost the same with the $C r m$ of farm machinery in Northern Italy.

The values repairs factor $1(R F 1)$ and repairs factor $2(R F 2)$ for $C r m$ model for farm machinery in Malaysian oil palm plantation were 1.4061 and 1.6588 , respectively.

Specifically, the findings of this study provide the researchers and plantation managers concerning repair costs data of farm machinery by different farm machinery sizes (small and mid-sizes). It also assists the oil palm plantations managers to select the economics size of farm machinery needed for running their daily field operations and predict their repair costs accurately. Generally, it gives a beneficial contribution to the oil palm plantation industry in developing strategic planning regarding the allocation and management of the overall costs of farm machinery.

This study focused in repair costs analysis on the basis of farm machinery sizes, it is, therefore, the need for further research is recommended to investigate the repair costs of 
farm machinery on the basis of different repair and maintenance standards practiced by oil palm plantations and also on the basis of various farm machinery makes and models that available in the plantations.

\section{ACKNOWLEDGMENT}

The authors would like to thanks all respondents in Melaka and Negeri Sembilan, Malaysia for their cooperation in providing us with their data for this study.

\section{REFERENCES}

[1] MPOB. "Economic and Industrial Development Division: Malaysia total area of oil palm planted in 2015". Available at: http://bepi.mpob.gov.my/index.php/en/statistics/area.html. Accessed in December 2016.

[2] FAOSTAT, "Machinery: Malaysia's import quantity in the year 2005-2009," [Online] Available: http://faostat3.fao.org/download///RM/E. Accessed: 2016.

[3] J.C. Siemens, W, Bowers, W, and R.G. Holmes, R. G. Machinery Management: 6th ed.: Deere \& Co. Moline, IL, USA. 2008, pp. 8.18.10 .

[4] D. Hunt and D. Wilson, Farm Power and Machinery Management. Waveland Press, Inc. Illinois, USA.m 2011. Pp.71-86

[5] F.M Inns, Operational aspects of tractor use in developing countries-A case for the small tractor, "The Agricultural Engineer (Summer), pp.52-54, 1978.

[6] A. Calcante, L. Fontanini, and F. Mazzetto, "Repair and maintenance costs of $4 \mathrm{wd}$ tractors in Northern Italy," Transactions of the ASABE, vol. 56, no. 2, pp. 355-362, 2013

[7] W. Bowers and D. R. Hunt, "Application of mathematical formulas to repair cost data," Transactions of the ASAE, vol. 13, no. 6, pp. 0806-0809, 1970.

[8] S. M. Ward, P. B. McNulty, and M. B. Cunney, "Repair cost of 2 and 4 WD tractors," Transactions of the ASABE, vol. 28, no. 4, pp. 10741076, 1985.
[9] S. A. Al-Suhaibani and M. F. Wahby, "Tractor repair and maintenance in Saudi Arabia," Applied Engineering in Agriculture, vol. 15 , no. 6, pp. 591-596, 1999 .

[10] ASABE, "Agricultural machinery management," ASABE Standards, vol. D496.3, pp. 1-6, 2011.

[11] M. Lips, "Repair and maintenance costs for nine agricultural machine types," Transactions of the ASABE, vol. 56, no. 4, pp. 1299-1370, 2013.

[12] A. Calcante, L. Fontanini, and F. Mazzetto, "Coefficients of repair and maintenance costs of self-propelled combine harvesters in Italy," Agricultural Engineering International, vol. 15, no. 3, pp. $141-147,2013$

[13] M. Lips, and F. Burose, "Repair and maintenance costs for agricultural machines, " International Journal of Agricultural Management, vol. 1, no.3, pp 40-46, 2012.

[14] ASABE, "Agricultural Management Machinery Data," ASABE Standard, vol. D497.7, pp. 1-8, 2011.

[15] G. M. Khoub bakht, H. Ahmadi, A. Akram, and M. Karimi, "Repair and maintenance cost models for mf 285 tractor: a case study in the central region of Iran," American-Eurasian Journal of Agricultural \& Environmental Science, vol. 4, no. 1, pp. 76-80, 2008.

[16] J. Pawlak, G. Pellizzi, and M. Fiala, "Development of agricultural mechanization to ensure a long-term world food supply," Proc. XI Meeting Club of Bologna, pp. 24-47, 2001.

[17] D.E., Pebrian, Yahya, A and Siang, T.C, "Workers' workload and productivity in oil palm cultivation in Malaysia," Journal of Agricultural Safety and Health vol 20, no. 4: 235-253,2014.

[18] D. E. Pebrian, A. Yahya, N. M. Nawi, T. C. Siang, and S. M. B. Gevao, "Monitoring and auditing human energy input for oil palm and rice production in Malaysia," The Philippine Agricultural Scientist, vol. 96, no. 3, pp. 282-289, 2011.

[19] L.N. Langemeier, and R.K. Taylor. A Look at Machinery Costs Manhattan, KS: Kansas State University. Farm Management Guide MF-842. 1998.

[20] R.Veloo, P. Selamat and M.R. Shahruddin, "Rising cost of plantation business, "The Planter, vol.89, no.1050, pp.661-671, 2013.

[21] R. Veloo, R and M. F Hitam, Plantation labor: Need for a management strategy. The Planter, vol. 88, no. 1031: 125-137, 2012. 